\title{
F-wave Latency Conduction Velocity of the Ulnar Nerve among Normal Sudanese Adults
}

\author{
Wafaa Abdel Raouf Hussein ${ }^{1}$, Ammar Eltahir ${ }^{2}$ \\ ${ }^{1}$ Assistant Professor of Human Physiology, Basic Sciences Department, Faculty of Dentistry, University of Khartoum \\ ${ }^{2}$ Physiology Department, Faculty of Medicine, University of Khartoum
}

\begin{abstract}
F-waves, one of the late responses produced by antidromic activation of Motoneurons by supramaximal stimulation, are one of the most frequently used studies in clinical neurophysiology. They are particularly useful for the diagnosis of proximal nerve lesions and have been found of use in diagnosis of certain types of peripheral neuropathy such as Guillian Barre Syndrome GBS, when other nerve conduction studies have been normal, as well in diabetic neuropathy. They are variable in latency, amplitude, and configuration, and are recorded over a muscle innervated by the stimulated nerve. This is the first study to date that evaluates F-wave Latency in normal Sudanese adults to determine the mean value for the F-latency conduction velocity, sex and age related changes in the F-latency conduction velocity, and the relationship between body height, span and F-wave latency. Values of F-latency conduction velocity obtained in this study reveals normal Sudanese figures similar to universal findings, with sex but no age related changes in F-latency conduction velocity, females showing faster conduction in females, and F-wave distal latency directly proportional to body height and span.
\end{abstract}

Keywords: F-Wave Latency, Ulnar Nerve Conduction, F-latency conduction velocity, Peripheral Neuropathy, Diabetic Neuropathy]

\section{Introduction}

Nerve conduction study is one of the electrodiagnostic studies, which can be of valuable asset in the diagnosis and follow up of neuromuscular diseases; however, it must be used as an extension of clinical evaluation and not as a routine test. ${ }^{(1)}$ Nerve conduction studies are basically performed to study the distal segment involvement. ${ }^{(2)}$ The late responses are preformed to study the proximal segment involvement, with 3 different late responses: $\mathrm{H}$ reflex, $\mathrm{F}$ wave and the axon reflex.. ${ }^{(2)}$ Out of this $\mathrm{H}$ reflex and $\mathrm{F}$ wave are preformed to study the proximal regions of nerves (i.e., portions of nerves near the spinal cord. $\mathrm{F}$ wave occurs after the CMAP (Compound Muscle Action Potential), resulting from antidromic stimulation of motor neurons involving conduction to and from spinal cord and occurs at the interface between peripheral and central nervous system. ${ }^{(2)}$

In a typical $\mathrm{F}$ wave study, a strong electrical stimulus (supramaximal stimulation) is applied to the skin surface above the distal portion of a nerve so that the impulse travels both distally (towards the muscle fiber) and proximally (back to the motor neurons of the spinal cord. (2)

F-wave has been found of use in diagnosis of certain types of peripheral neuropathy (Guillian Barre Syndrome GBS), when other nerve conduction studies have been normal. ${ }^{(3)}$ The nerve conduction velocity is also helpful in the assessment of peripheral nerve injury and diagnosis of traumatic spinal cord injuries. ${ }^{(1,4)}$ The degree of slowing of the nerve conduction velocity is also helpful in assessing the main pathology; whereas very minimal slowing $(>35 \mathrm{~m} / \mathrm{sec})$ is recognized in alcoholic degeneration (alcoholic), a markedly slowing $(>30 \mathrm{~m} / \mathrm{sec}$ ) is shown in segmental demylination (GBS). ${ }^{(5)}$ Studies were also done on the F-wave to investigate the usefulness of new parameter, the ratio of motor nerve conduction velocity to F-latency conduction velocity in diabetic neuropathy. ${ }^{(6)}$ Nerve conduction velocity is also helpful in the study of families that have peripheral neuropathy as a part of genetically determined illness especially in detection of asymptomatic Charcot Marie tooth disease. ${ }^{(7)}$

No previous studies were done in F-wave velocity among normal Sudanese studies. This study is the first to date among normal Sudanese adults to determine the mean value for the F-latency conduction velocity, to find out sex and age related changes in the F-latency conduction velocity, and to determine the relationship between body height, span and F-wave latency.

\section{Subjects and Methods}

An observational study was performed on motor nerve conduction on a sample of hundred normal Sudanese adults (males $=55$ ) (females $=45$ ) with a mean age of $38.29 \pm 1.24$ and $36.44 \pm 1.18$. Right and left ulnar nerve conduction velocity was calculated in forty five subject of the same sample (males=22) (females=23), as well as measurement of body height and span was performed. Selection of the subjects was on voluntary bases, whereby any person fulfill the inclusion criteria of being a Sudanese normal adult with no signs or symptoms or history of neurological disease, was considered completing the desired sample.

Recording took place, using electromyography machine (EMG) Medelec, MS92, in the department of physiology, Faculty of medicine, University of Khartoum. The F-wave is easily obtained by stimulating the distal portion of the ulnar nerve, using motor nerve conduction set-up and changing sweep velocity (msec/division) to 5-10 msec and sensitivity (uv/division) to 500uv. High filter KHZ of 10 and low KHZ OF 20. Stimulus rate of one/two seconds $(1 / 2 \mathrm{sec})$ to avoid block response stimulation of the ulnar nerve.

\section{Volume 5 Issue 2, February 2016}




\section{International Journal of Science and Research (IJSR) \\ ISSN (Online) : 2319-7064}

Index Copernicus Value (2013) : 6.14 | Impact Factor (2014) : 5.611

Recording take place with supramaximal intensity and Fwave is observed.

F-wave was obtained 10 times and latency was recorded from the start of the stimulus to the onset of the initial deflection of the F-wave, with the shortest latency. Fwave latency should be compared with other normal values. The easiest comparison is to make F-wave latency between the right and left sides, a more than $2 \mathrm{msec}$ difference between the right and left, is significant ${ }^{(8)}$

\section{Results}

Comparisons in F-wave distal latencies and F-latency conduction velocities between males and females right and left ulnar nerve showed high significant difference [Tables 1, 2].
Table 1: Comparisons in right and left $\mathrm{F}$-wave distal latencies between males and females ulnar nerves

\begin{tabular}{|c|c|c|c|c|}
\hline Test & D.L.R.T (msec) & \multicolumn{2}{c|}{ D.L.L.T (msec) } \\
\hline Sex & Males & Females & Males & Females \\
\hline number & 55 & 45 & 55 & 45 \\
\hline Mean \pm SE & $28.81 \pm 0.25$ & $26.31 \pm 0.28$ & $28.63 \pm 0.26$ & $26.16 \pm 0.28$ \\
\hline & \multicolumn{2}{|c|}{$\mathrm{P}=0.000$} & \multicolumn{2}{|c|}{$\mathrm{P}=0.000$} \\
\hline \multicolumn{3}{|c}{ D.L.R.T= distal latency right *D.L.L.T = distal latency left * } \\
\hline
\end{tabular}

Table 2: Comparisons in right and left $\mathrm{F}$-wave conduction velocity between males and females ulnar nerves

\begin{tabular}{|c|c|c|c|c|}
\hline Test & NCV.RT m/sec & NCV.LT m/sec \\
\hline Sex & Males & Females & Males & Females \\
\hline number & 22 & 23 & 22 & 23 \\
\hline Mean \pm SE & $44.51 \pm 0.57$ & $49.25 \pm 0.74$ & $45.05 \pm 0.60$ & $48.52 \pm 0.52$ \\
\hline \multicolumn{4}{|c|}{$\mathrm{P}<0.05$} & \multicolumn{2}{c|}{$\mathrm{P}<0.05$} \\
\hline \multicolumn{2}{|c|}{ NCV.RT; NCV.LT $=$ nerve conduction velocity right and left * } \\
\hline
\end{tabular}

There is a highly significant direct correlation of F-distal latency with span and height [Figures 1, 2].

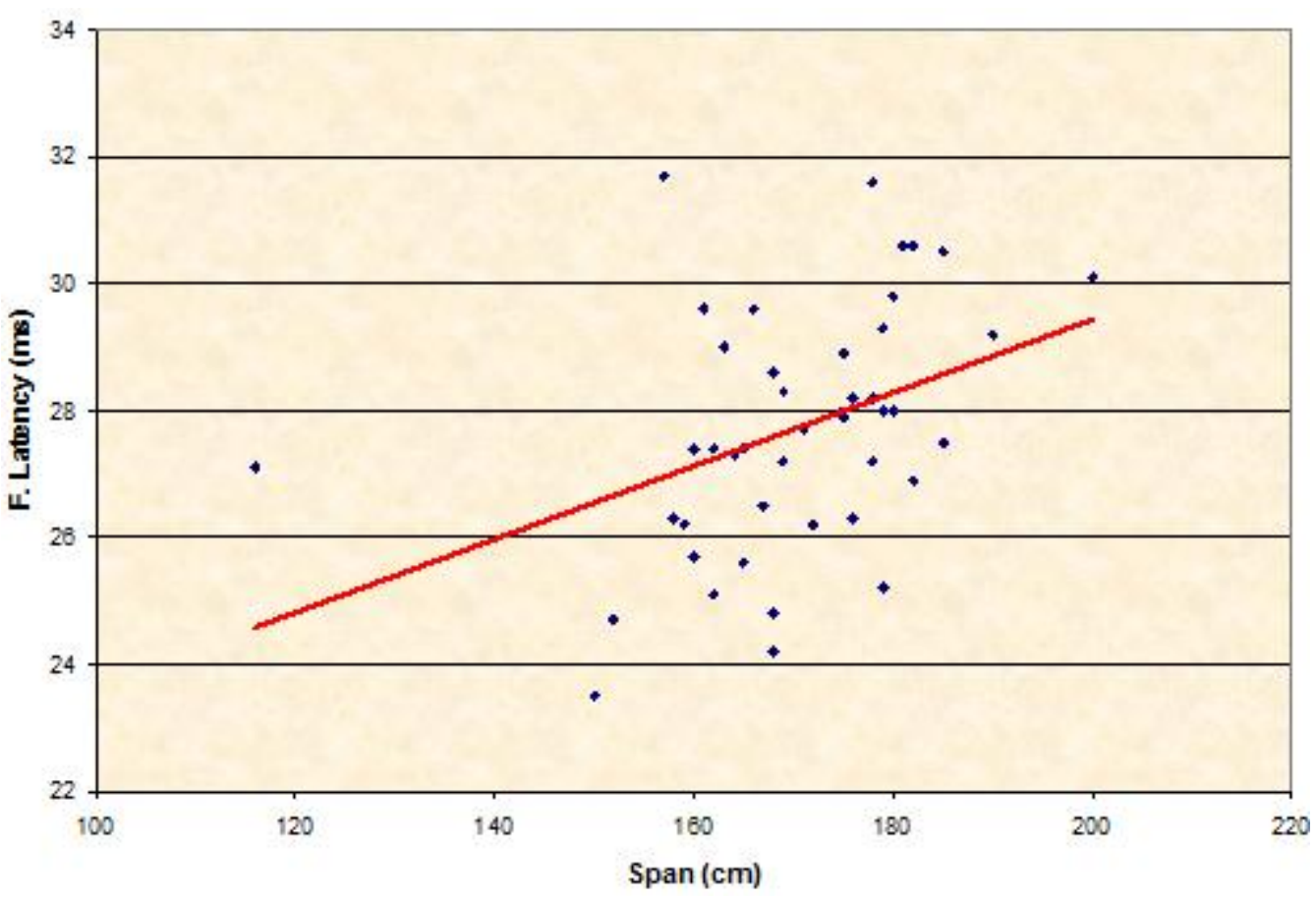

Figure 1: Relation of F. distal latency to Span

R Square $=0.16706$

Prob. > F

$\mathrm{P}<.0001$ 


\section{International Journal of Science and Research (IJSR) \\ ISSN (Online) : 2319-7064}

Index Copernicus Value (2013) : 6.14 | Impact Factor (2014) : 5.611

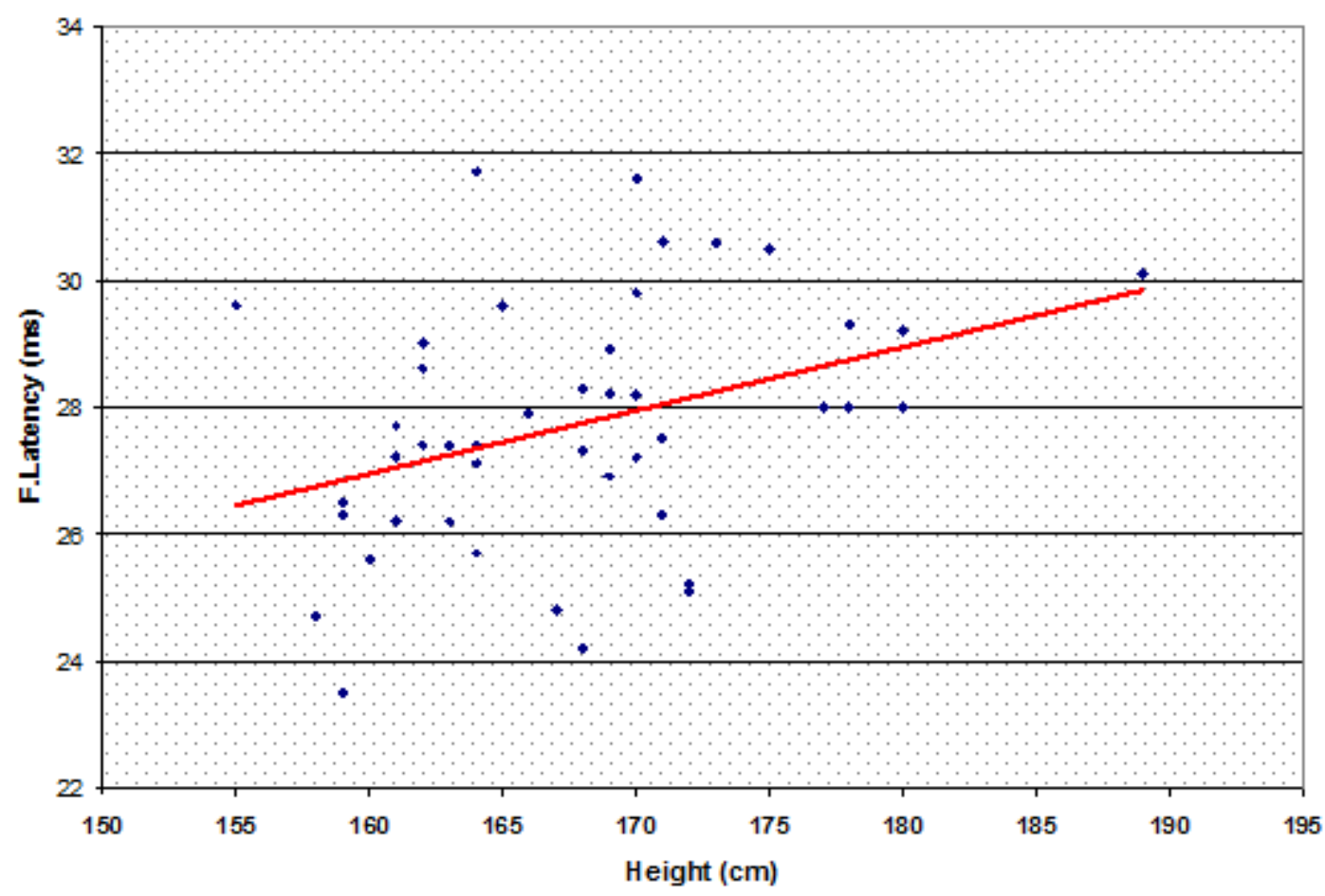

Figure 2: Relation of F. distal latency to Height

$\mathrm{R}$ Square $=0.1296$

$\mathrm{P}<.0001$

Prob. $>$ T

\section{Discussion}

F-wave latency as one of the main components of the Fwave, had attracted our attention to do more study on that particular parameter and its relationships. It has been observed that F latency vary with the height of the patient, with F responses longer in tall patients. The upper limit of minimal F latency is $31 \mathrm{~ms}$ for female and $34.4 \mathrm{~ms}$ in normal males, and the right to left asymmetry of minimal F latency exceeding $2 \mathrm{~ms}$ in hand and $4 \mathrm{~ms}$ in foot is considered abnormal. ${ }^{(9)}$ Our study revealed a significant difference in span between males and females, $\{170.3 \pm$ $(1.83 \mathrm{SE})$ and $156.6 \pm$ (4.73 SE) \} centimeters, respectively. The mean value among Sudanese adults of F-distal latency $\{27.6 \pm(0.23 \mathrm{SE}) \mathrm{msec}$ and of conduction velocity $\{46.9 \pm(0.74 \mathrm{SE}) \mathrm{m} / \mathrm{sec}\}$, thus coinciding with known international figures with upper limit $51.8 \mathrm{~m} / \mathrm{sec}$ and lower limit $39.2 \mathrm{~m} / \mathrm{sec}$. A direct and strong relationship between F-distal latency and body height and span (Fig 1,2) could be found in this study again coinciding with other studies ${ }^{9-11)}$. The study also revealed sex but no age related changes in the F-latency conduction velocity, with faster conduction velocity in females (Table $1,2)$. This finding coincides with our previous study ${ }^{(12)}$ and other related studies on the relation of F-latency with age and sex which revealed no age related changes but shorter latency in females' ${ }^{(11,13,14) .}$ On the other hand some studies had related F-latency conduction velocity to age $\left({ }^{15)}\right.$.Whether sex related changes in the F-latency conduction velocity is related to the difference in body stature between males and females or not, is a question that still remains to be answered.

\section{References}

[1] SJ. Electromyographic tests in neuromuscular disease. In: Pourmand R. ed. Neuromuscular disease expert clinicians' view. Boston: Butter worth/ Heinemann, 2001: 1-49.

[2] Taksande B, Jain A. The "F" WAVE: Clinical Importance. The Internet Journal of Neurology. 2008 Volume 10 Number 2.

[3] Lachman T, Shahani B. T, Young R.R. Late responses as aids to diagnosis in peripheral neuropath J. Neurosurgphsychiatrs 1980; 48: 159-162.

[4] Currt A, KeCk M E, Dietz V. Clinical value of F wave recordings in traumatic cervical spinal cord injury. Electroencephalogr-Clin-neurophysiol 1997; 105: 189-93.

[5] Dillmann U, Oh lamann D, Hamann GF, Schimrigk $\mathrm{K}$. Value of magnetic stimulation and F-wave determination in diagnosis of proximal demyelinating lesion. Follo-up of acute Guillain-Barre polyradiculitis. Neurologische Universitatsklinik Homburg Sarr. Nervenarzt 1998; 69: 338-41.

[6] Ohgaki K, Nakano K, Shigeta H, et al. Ratio of motor nerve conduction velocity to $\mathrm{F}$ - wave conduction velocity in diabetic neuropathy.. Diabetes-Care1998; 21: 6158.

[7] Dyck P. J, lambert E.H. and Mulder D.W. Charcot. Marie tooth disease nerve conduction and Chemical studies of a large Kinship; Neurology 1963; 23:1-11.

[8] Fisher M.A, Shrivole A. J, Terxera C, Grainer L.S. The F. response is a clinical useful physiological parameter for the evaluation of radiculer injury. 


\section{International Journal of Science and Research (IJSR) \\ ISSN (Online) : 2319-7064}

Index Copernicus Value (2013) : 6.14 | Impact Factor (2014) : 5.611

Electromyogr. Clin. Neurophysiology 1997; 19:6575.

[9] Puksa L, Stålberg E, Falck B. Reference values of Fwave parameters in healthy subjects ClinNeurophysiol 2003; 114: 1079-90.

[10] Peioglou-Harmoussi S, Howel D, Fawcett PR, Barwich DD. F-response behaviour in a control population. J Neurosurg Psychiatry 1985; 48 : 11528.

[11] Alavian-Ghavanini MR, Samadzaadeh S, AlavianGhavanini A. Normal values of F-wave in upper extremities of 50 healthy individuals. Iran ElectromyogrClinNeurophysiol 1998; 38: 305-8.

[12] Khalil WAH, Eltahir AMA. Ulnar Nerve F-Wave Response of Normal Sudanese Adults. MAJMAAH JOURNAL OF HEALTH SCIENCE, Vol 2, Issue 2, 2014

[13] Anantharaman V, Bhatnagar OP. Influence of age on residual latency. Indian J Physiol. Pharmacol 1977; 21: 141-3.

[14]Bruno Greqori, Stefano Pro, FrancesocoBombeelli, Maurizio La Rica, NeriAccomero.Vep latency, sex and head size. Clinical neurophysiology 2006; 117:1154-57.

[15]Zappia M, Valentino P, Marchello LP, Paniccia M, Montagna. F-wave normative studies in different nerves of healthy subjects. ElectroencephalogrClinNeurophysio 1993; 89: 67-72 